\title{
Meta-analysis of broad-spectrum antibiotic therapy in patients with active inflammatory bowel disease
}

\author{
SHENG-LAN WANG, ZHI-RONG WANG and CHANG-QING YANG \\ Division of Gastroenterology and Digestive Diseases Institute, Tongji Hospital of \\ Tongji University School of Medicine, Shanghai 200065, P.R. China
}

Received July 1, 2012; Accepted September 12, 2012

DOI: $10.3892 /$ etm.2012.718

\begin{abstract}
Patients with Crohn's disease (CD) or ulcerative colitis (UC) undergo various therapies, including antibiotic therapy. This meta-analysis of controlled clinical trials was conducted to evaluate whether the use of antibacterial therapy improves the clinical symptoms of inflammatory bowel disease (IBD). The Medline and Scopus databases were searched and a systematic review was performed. Randomized, controlled trials in which antibiotic therapy was compared with placebo were investigated. A total of 10 randomized, placebo-controlled clinical trials for $\mathrm{CD}$ were included in the meta-analysis. The pooling of the data from these trials yielded an odds ratio (OR) of 1.35 [95\% confidence interval (CI), 1.16-1.58] for antibiotic therapy compared with placebo in patients with CD. Furthermore, nine randomized placebo-controlled clinical trials for UC matched our criteria and were included in the analysis. The pooling of the data from these trials yielded an OR of 2.17 (95\% CI, 1.54-3.05) in favor of antibiotic therapy. These results suggest that antibiotics improve clinical outcomes in patients with IBD.
\end{abstract}

\section{Introduction}

Crohn's disease (CD) and ulcerative colitis (UC) are covered by the classification of inflammatory bowel disease (IBD). IBD is an idiopathic disease resulting in intestinal mucosal inflammation and loss of the barrier function. The exact mechanisms of the induction and development of IBD are not yet fully understood. Multiple factors may contribute to this condition. An immunological disorder coupled with intolerance to intestinal flora appear to be the most significant. In certain cases, they are associated with gene mutations induced by environmental factors or pathogenesis. The terminal ileum and colon have a

Correspondence to: Dr Chang-Qing Yang or Dr Zhi-Rong Wang, Division of Gastroenterology and Digestive Diseases Institute, Tongji Hospital, Tongji University School of Medicine, 389 Xincun Road, Puotuo District, Shanghai 200065, P.R. China

E-mail: docwangwang@yeah.net

E-mail: cqyang@tongji.edu.cn

Key words: antibiotic therapy, Crohn's disease, ulcerative colitis high bacterial content, which in IBD stimulates inflammation in the intestinal lumen (1). A study of IBD patients revealed that the loss of immune tolerance to symbiotic bacteria involved increased T-cell and humoral immune responses (2). The chronic idiopathic IBDs, CD and UC, appear to involve an over-active immune response to bacterial antigens in genetically susceptible individuals (3). The therapy of IBDs typically comprises immunosuppressive drugs, but clinicians tend also to use antibiotics as certain symptoms, including fever, purulent stools, abscesses and other signs of infection, have been considered to be caused by bacteria (1).

Although scientists have debated whether bacteria are the primary cause of $\mathrm{CD}$, they cause only a superimposed bacterial infection of the lesions while the disease is caused by an overaggressive immune response to the bacteria. Several studies have examined the effects of anti-tuberculosis treatment on IBD, but these trials have generated conflicting results. Animal data support the anti-inflammatory effects of a small number of antibiotics, while in studies of $\mathrm{CD}$, anti-inflammatory effects have been shown in patients using metronidazole and ciprofloxacin (4). However, there is no definite proof of systemic antibiotics as the main treatment due to lack of valid data on $\mathrm{CD}$.

The objective of this meta-analysis was to perform a systematic review and meta-analysis of randomized, placebocontrolled clinical trials to assess the effectiveness of antibiotic therapy in patients with CD.

\section{Materials and methods}

Literature search. Only randomized, controlled trials which compared antibiotic therapy to placebo in patients with CD or UC were included. We searched the Medline and Scopus databases from 1970 to 2010 using keywords that denote IBDs, antibacterial and antimycobacterial drugs, antibacterial activity, metronidazole and ciprofloxacin. The language used was English.

Data abstraction. The standardized data abstraction form and main outcome data, including treatment programs, sample size and results, were selected by two independent observers.

Ethambutol, isoniazid and rifamycins (including rifampicin and rifabutin) were considered to be classic drugs against infection with Mycobacterium tuberculosis, and trials 
Table I. Summary of randomized, controlled trials included in the meta-analysis of Crohn's disease.

\begin{tabular}{|c|c|c|c|c|c|c|c|}
\hline \multirow[b]{2}{*}{ Author (ref) } & \multirow{2}{*}{$\begin{array}{l}\text { Mean } \\
\text { age }\end{array}$} & \multirow{2}{*}{$\begin{array}{l}\text { Gender } \\
(\mathrm{M} / \mathrm{F})\end{array}$} & \multirow[b]{2}{*}{ Regimens } & \multirow{2}{*}{$\begin{array}{l}\text { Concomitant } \\
\text { therapy }\end{array}$} & \multirow[b]{2}{*}{ Duration } & \multicolumn{2}{|c|}{ Clinical improvement } \\
\hline & & & & & & Antibiotics & Placebo \\
\hline Arnold et al, 2002 (9) & 45.2 & $28 / 19$ & Cipro 500 mg b.i.d. & Prednisone & 4 weeks & $21 / 28$ & $5 / 19$ \\
\hline Prantera et al, 2006 (8) & $38 \pm 12$ & $16 / 11$ & Rifaximin 800 mg b.i.d. & Aminosalicylate & 12 weeks & $14 / 27$ & $9 / 27$ \\
\hline West et al, 2004 (10) & 34 & $12 / 12$ & Cipro 500 mg b.i.d. & Infliximab & 6 weeks & $1 / 11$ & $2 / 13$ \\
\hline Steinhart et al, 2002 (7) & 32 & $57 / 77$ & $\begin{array}{l}\text { Cipro } 500 \text { mg b.i.d. + } \\
\text { metro } 500 \mathrm{mg} \text { b.i.d. }\end{array}$ & Budesonide & 8 weeks & $22 / 66$ & $21 / 64$ \\
\hline Leiper et al, 2008 (11) & 34 & $17 / 24$ & Clari 1 g/day & & 12 weeks & $5 / 19$ & $6 / 22$ \\
\hline Goodgame et al, 2001 (12) & $39.4 \pm 9.2$ & $18 / 13$ & $\begin{array}{l}\text { Clari } 500 \mathrm{mg} \text { b.i.d. + } \\
\text { ethambutol } 15 \mathrm{mg} / \mathrm{kg}\end{array}$ & & 12 weeks & $5 / 9$ & $6 / 9$ \\
\hline Blichfeldt et al, 1978 (13) & 27.5 & $8 / 12$ & Metro 250 mg q.i.d. & Prednisone & 8 weeks & $11 / 20$ & $10 / 20$ \\
\hline Ambrose et al, 1985 (14) & 36.5 & $13 / 22$ & Metro 400 mg b.i.d. & & $\begin{array}{l}2 \text { weeks } \\
4 \text { weeks } \\
6 \text { weeks }\end{array}$ & $\begin{array}{r}12 / 18 \\
8 / 18 \\
10 / 16\end{array}$ & $\begin{array}{l}6 / 17 \\
7 / 17 \\
7 / 14\end{array}$ \\
\hline Ambrose et al, 1985 (14) & 37.0 & $12 / 21$ & Sulfa 960 mg b.i.d. & & $\begin{array}{l}2 \text { weeks } \\
4 \text { weeks }\end{array}$ & $\begin{array}{l}10 / 16 \\
10 / 16\end{array}$ & $\begin{array}{l}6 / 17 \\
7 / 17\end{array}$ \\
\hline Sutherland et al, 1991 (6) & NA & NA & Metro $10-20$ mg/kg/day & & 16 weeks & $18 / 63$ & $6 / 36$ \\
\hline Selby et al, 2007 (5) & $36.5 \pm 11.3$ & $101 / 112$ & $\begin{array}{l}\text { Clari } 750 \mathrm{mg} / \text { day }+ \\
\text { rifampicin } 450 \mathrm{mg} / \text { day }+ \\
\text { clofa } 50 \mathrm{mg} / \text { day }\end{array}$ & Prednisone & 16 weeks & $67 / 102$ & $55 / 111$ \\
\hline
\end{tabular}

Cipro, ciprofloxacin; metro, metronidazole; clari, clarithromycin; sulfa, sulfamethoxazole; clofa, clofazimine; NA, not available.

Table II. Characteristics of studies included in the meta-analysis of ulcerative colitis.

\begin{tabular}{|c|c|c|c|c|c|c|c|}
\hline \multirow[b]{2}{*}{ Author (ref) } & \multirow{2}{*}{$\begin{array}{l}\text { Mean } \\
\text { age }\end{array}$} & \multirow{2}{*}{$\begin{array}{l}\text { Gender } \\
(\mathrm{M} / \mathrm{F})\end{array}$} & \multirow[b]{2}{*}{ Regimens } & \multirow{2}{*}{$\begin{array}{l}\text { Concomitant } \\
\text { therapy }\end{array}$} & \multirow[b]{2}{*}{ Duration } & \multicolumn{2}{|c|}{ Clinical improvement } \\
\hline & & & & & & Antibiotics & Placebo \\
\hline Burke et al, 1990 (28) & 43.5 & $28 / 19$ & Tobra 120 mg t.i.d. & Corticosteroids & 7 days & $31 / 42$ & $18 / 42$ \\
\hline Ohkusa et al, 2005 (31) & 39.5 & $12 / 8$ & $\begin{array}{l}\text { Amoxi } 500 \text { mg t.i.d. + } \\
\text { Tetra } 500 \mathrm{mg} \text { t.i.d. + } \\
\text { metro } 250 \mathrm{mg} \text { t.i.d. }\end{array}$ & $\begin{array}{l}\text { Aminosalicylate + } \\
\text { corticosteroids }\end{array}$ & 14 days & $9 / 10$ & $5 / 10$ \\
\hline Mantzaris et al, 2001 (26) & 41.5 & $26 / 29$ & Cipro 400 mg b.i.d. & & 10 days & $23 / 29$ & $20 / 26$ \\
\hline Mantzaris et al, 1997 (25) & 41.5 & $33 / 37$ & Rifaximin $400 \mathrm{mg}$ b.i.d. & Corticosteroids & 14 days & $24 / 34$ & $26 / 36$ \\
\hline Gionchetti et al, 1999 (29) & & & Cipro 500-750 mg b.i.d. & & 10 days & $9 / 14$ & $5 / 12$ \\
\hline Turunen et al, 1998 (30) & 34.2 & $58 / 25$ & Cipro 500-750 mg b.i.d. & $\begin{array}{l}\text { Corticosteroids } \\
\text { Aminosalicylate }\end{array}$ & 180 days & $30 / 38$ & $25 / 45$ \\
\hline Ohkusa et al, 2010 (32) & NA & NA & $\begin{array}{l}\text { Amoxi } 500 \mathrm{mg} \text { t.i.d. + } \\
\text { tetra } 500 \mathrm{mg} \text { t.i.d. }+ \\
\text { metro } 250 \mathrm{mg} \text { t.i.d. }\end{array}$ & & 90 days & $47 / 105$ & $24 / 105$ \\
\hline Chapman et al, 1986 (24) & 46.0 & $19 / 20$ & Metro 500 mg t.i.d. i.v. & Prednisone & 5 days & $14 / 19$ & $14 / 20$ \\
\hline Mantzaris et al, 1994 (27) & NA & NA & $\begin{array}{l}\text { Metro } 0.5 \mathrm{~g} \text { t.i.d. i.v. }+ \\
\text { tobra } 4 \mathrm{mg} / \mathrm{kg} \text { t.i.d. }\end{array}$ & Hydrocortisone & 10 days & $12 / 19$ & $13 / 20$ \\
\hline
\end{tabular}

Tobra, tobramycin; amoxi, amoxicillin; tetra, tetracycline; metro, metronidazole; cipro, ciprofloxacin; NA, not available.

of antituberculosis drugs were included in the meta-analysis. Similarly, nitroimidazoles (metronidazole), macrolides (clar- ithromycin) and riminophenazines (clofazimine), were also analyzed together (Tables I and II). 


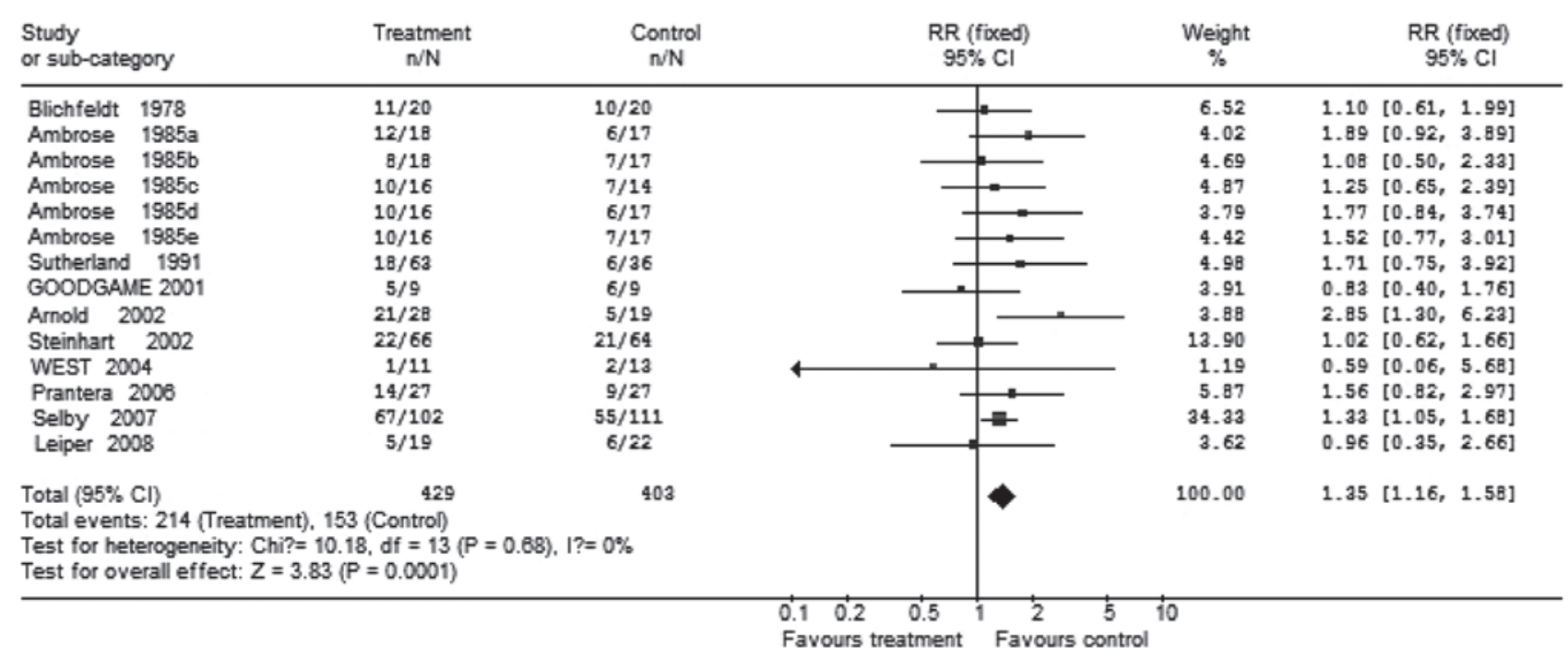

Figure 1. Analysis of trials based on the use of antibiotic therapy with or without a tapering course of corticosteroids in Crohn's disease. RR, risk ratio; CI, confidence interval.

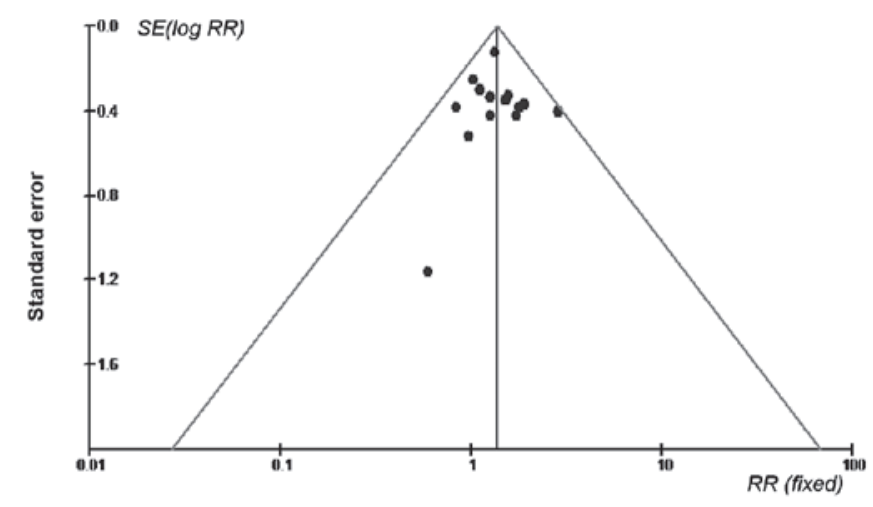

Figure 2. Funnel plot of indicators of bias for the outcome of clinical improvement in studies of antibiotic therapy for Crohn's disease. RR, risk ratio.

Statistical analysis. Homogeneity was assessed using a $\chi^{2}$ test of homogeneity and the graphics were displayed simultaneously. A pooled estimate of the odds ratio (OR) was calculated and applied to a Mantel-Haenszel method test. Study results are presented as ORs with $95 \%$ confidence intervals (CIs). For studies with continuous outcome measures, results were converted to ORs. The log OR corresponds to a constant multiplied by the standardized difference between means.

\section{Results}

All included studies had a double-blind design. The trials involved a total of 832 patients with CD who were randomized to receive broad-spectrum antibiotic therapy; 429 patients were treated with antimicrobials while 403 patients received placebo. In the antibiotic group, 39 (9.1\%) received ciprofloxacin, 135 (31\%) patients received metronidazole alone, $32(7.4 \%)$ received cotrimoxazole alone, 19 (4.4\%) patients received clarithromycin alone and 66 (15.3\%) patients received metronidazole plus ciprofloxacin. In these trials, some patients received concomitant therapy and some did not. Clinical improvement occurred in 56.1\% (214/429) of patients in the antibiotic group and $37.9 \%$ (153/403) of patients in the placebo group. The summary OR for clinical improvement with any antibiotic therapy in the trial was 1.35 (95\% CI, 1.16-1.58), The Breslow-Day test for heterogeneity indicated that the studies were not significantly heterogeneous (Figs. 1 and 2).

A total of 626 patients taking part in trials for UC were randomized to receive antibiotics; 310 patients were treated with antibiotics and 316 patients received placebo. In those who received antibiotics, 101 (32.6\%) received ciprofloxacin, $115(37.1 \%)$ received amoxicillin plus tetracycline plus metronidazole, $42(13.5 \%)$ received tobramycin alone and 19 $(6.1 \%)$ received metronidazole alone. Remission was induced in $64.2 \%$ of the patients treated with antibiotics, compared with $47.5 \%$ of the placebo group. The pooling of these trials yielded an OR of 2.17 (95\% CI, 1.54-3.05) in favor of antibiotic therapy. The Breslow-day test for heterogeneity revealed that the studies were statistically homogeneous and may be combined (Figs. 3 and 4).

\section{Discussion}

Crohn's disease. The majority of this work has been conducted using metronidazole, ciprofloxacin or clarithromycin alone or in combination. The two antibiotics most commonly used in the treatment of CD are metronidazole and ciprofloxacin. These antibiotics are active against two of the bacterial species suspected to be involved in the pathogenesis and, at least, relieve the symptoms of CD. Their use is widely accepted for the treatment of perianal fistula and colitis, although there is incontrovertible evidence supporting their use for these conditions.

The few randomized controlled trials to study metronidazole and/or ciprofloxacin have mostly presented negative results (5), although the treatment has been reported to be more effective in those patients whose disease involved the colon $(6,7)$. 


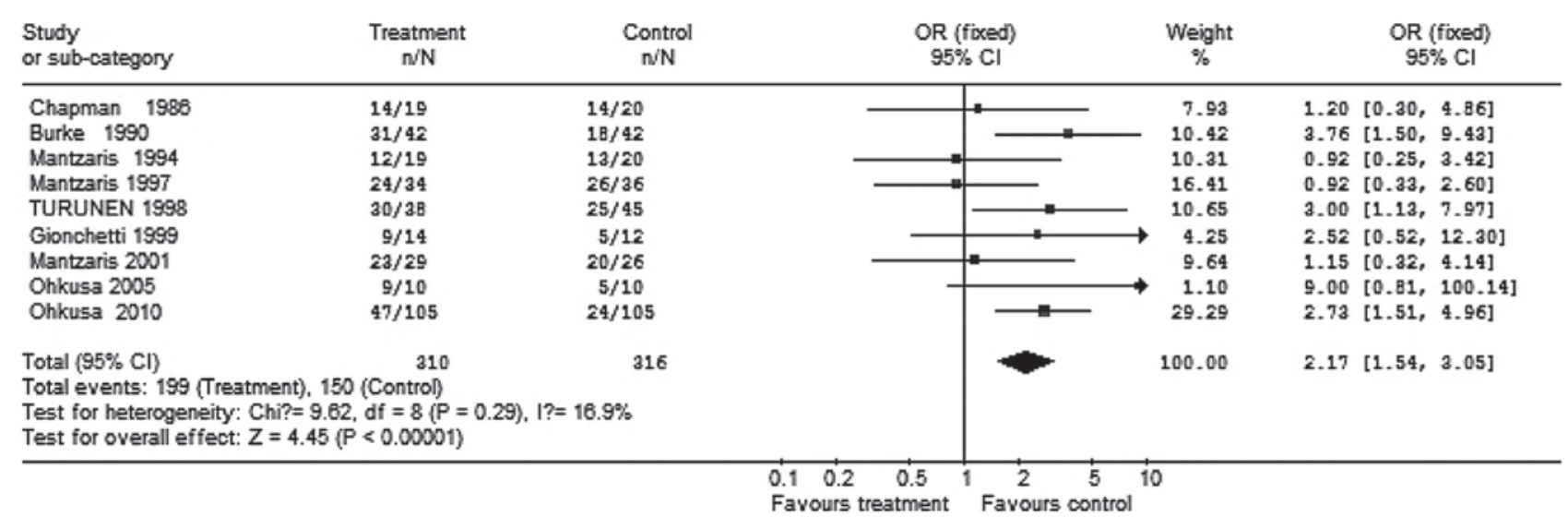

Figure 3. Individual and pooled odds ratios (ORs) for clinical remission in studies that considered antibiotic therapy in ulcerative colitis. CI, confidence interval.

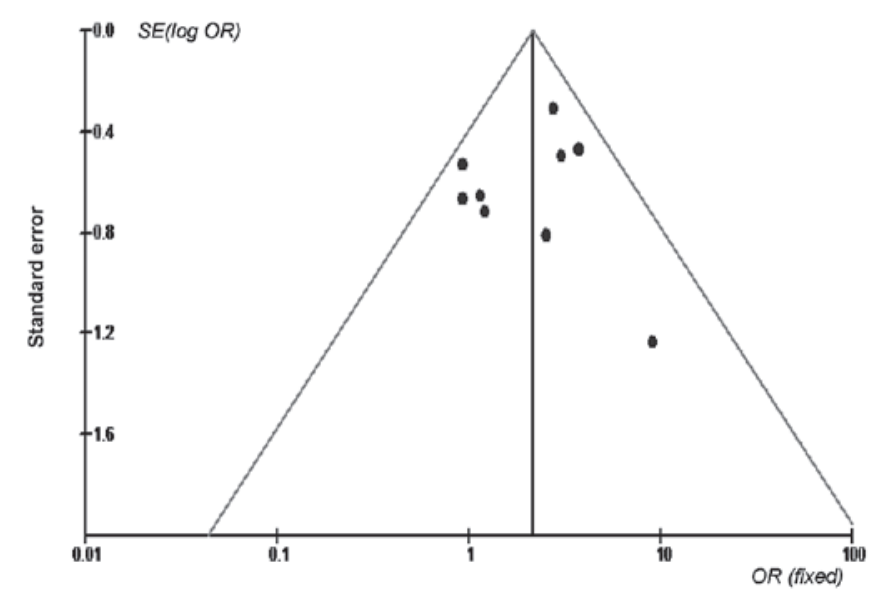

Figure 4. Funnel plot of indicators of bias for the outcome of clinical improvement in studies of antibiotic therapy for ulcerative colitis. OR, odds ratio; CI, confidence interval.

One study made use of rifaximin, a non-absorbed rifamycin drug with a broad spectrum of activity against Gram-positive, Gram-negative and even colonic anaerobic bacteria. Owing to the fact that it is not absorbed, systemic adverse effects are rare. In a double-blind, placebo-controlled trial reported by Prantera et al (8), $83 \mathrm{CD}$ patients were divided into 3 groups: group A received rifaximin, $800 \mathrm{mg}$ once a day; group B received rifaximin, $400 \mathrm{mg}$ twice daily; and group $\mathrm{C}$ received placebo. Remission rates were significantly higher $(52 \%)$ in group B than in group A (32\%) and in the placebo group (33\%) (8). Thus, the antibiotics with cell activity, including the macrolide antibiotics azithromycin and clarithromycin, may provide a more effective chemotherapy. Based on the role of intestinal microflora in the pathogenesis of $\mathrm{CD}$, the use of antibiotics or combined therapy, appears to be a rational strategy. In a previously published study, ciprofloxacin was shown to be effective when added to the existing medium-active treatment in therapy-resistant CD patients (9). Ciprofloxacin, a quinolone drug, is clinically effective in preventing the growth of intestinal bacteria and appears to have immunomodulatory properties. Accumulating evidence supports its role as the primary treatment for $\mathrm{CD}$. For example, in a prospective study by Colombel et al (16), ciprofloxacin (500 mg twice daily) was as effective as mesalazine ( $4 \mathrm{~g} /$ day) and induced remission in patients with mild to moderate CD.

Two important observations have strengthened the bacterial hypothesis for CD. Firstly, genetic studies have identified mutations in the NOD2 gene and the IRGM and ATG16L1 autophagy genes (17). These mutations mean that cells do not contain intracellular bacterial replication, and may have defects in their ability to eliminate bacteria (18). Secondly, an increased number of mucosa-associated $E$. coli have been identified in patients with IBD (19).

In addition to additional data being required to confirm the effectiveness of antibiotics in the treatment of CD, there is the emergence of resistant bacterial strains and the possible infection by Clostridium difficile to be considered. A study has reported the previous use of antibiotics by the majority of a group of IBD patients with Clostridium difficile infection (20). In an uncontrolled trial, antibiotic therapy resulted in clinical remission in 49 cases (68\%) (21). In the same study, 55 patients (76\%) showed a clinical response, which was higher in those patients who were also taking steroids (26/29) than those individuals who were not (29/43).

A large amount of data support the use of antibiotics in patients with $\mathrm{CD}$ and with diverticulitis. Antibiotics may act via different pathways in patients with $C D$. They may inhibit the bacteria linked to the pathological processes of the disease or simply lower the luminal bacterial overgrowth. The suppression of intestinal flora may reduce the strength of certain symptoms, including pain and diarrhea.

In our analysis, $C D$ patients undergoing antibacterial therapy are 1.35 -fold more likely to experience clinical remission than patients who are not undergoing antibacterial therapy. Homogeneity among the trials was established based on a graphic display and statistical tests. In addition, the meta-analysis of short-term antimicrobial use also revealed that treatment with antibiotics was effective in the induction of clinical remission. These results were clinically and statistically significant.

Whether antibiotics are of actual benefit remains to be determined since only a few controlled trials have been completed. Many used a small number of volunteers or used subgroups which were not always clearly defined. Antibiotic use has predominantly involved metronidazole or ciproflox- 
acin, and many patients cannot tolerate these drugs for a long duration. Therefore, these antibiotics are used in the treatment of ileal, ileocolonic and colonic CD (22).

Ulcerative colitis. Several different antibiotics, alone and in combination, have been evaluated in the primary and adjuvant treatment of active UC. The routine use of antibiotics is not recommended in mild or moderate UC. In a prospective, double-blind, randomized controlled trial reported by Gilat et al (23), oral metronidazole and sulfasalazine were used for the outpatient management of mild to moderate UC. This revealed that metronidazole was significantly less effective than sulfasalazine by endoscopic and clinical criteria.

In a randomized controlled trial reported by Chapman et al (24), 39 patients with severe UC were treated with either intravenous metronidazole (500 mg every $8 \mathrm{~h}$ ) or placebo as an adjunct to intravenous steroids for 5 days. No significant difference was observed in clinical improvement between the two groups. In two randomized controlled trials reported by Mantzaris et al $(25,26)$, patients with mild to severe acute UC received either oral or intravenous ciprofloxacin for 2 weeks as an adjunct to corticoid therapy. No significant difference in clinical improvement was observed, with $71 \%(24 / 34)$ and $79 \%(23 / 29)$ of the patients in the ciprofloxacin-treated group and $72 \%(26 / 36)$ and $77 \%(20 / 26)$ of the patients in the placebo-treated group achieving remission. The authors concluded that a short course of oral ciprofloxacin treatment did not appear to increase the proportion of patients with active UC going into remission. In another study, the combination of intravenous metronidazole and tobramycin as an adjunct to corticosteroids was not found to be effective in causing clinical improvement compared with placebo after 10 days of therapy in the treatment of severe UC (27).

However, antibiotics may have a certain benefit as adjuncts to standard anti-inflammatory treatment. Burke et al (28) reported a study in which 84 cases of acute UC were randomized to receive oral tobramycin or placebo for 7 days as an adjunct to steroidal therapy. When evaluated 18-21 days after the end of treatment, $31 / 42$ patients $(74 \%)$ in the tobramycin group and $18 / 42$ patients $(43 \%)$ in the placebo group had achieved clinical remission $(\mathrm{p}=0.008)$.

Despite considerable evidence for the involvement of bacteria in UC, broad-spectrum antibiotics are usually not used for the treatment of this disease; severe cases are the exception. Only a few antibiotics have been used in the treatment of UC, whether individually or in combination. One trial has shown that rifaxamin is beneficial in the treatment of UC (29). Turunen et al (30) performed a randomized, controlled trial which suggested that ciprofloxacin is beneficial as an adjunctive treatment for active UC during the first 6-month period of administration. At 6 months, the treatment-failure rate in the ciprofloxacin-treated group was $21 \%$ (8/38 patients), which was significantly lower than the placebo group rate of $44 \%$ (20/45 patients). The authors concluded that the use of ciprofloxacin therapy for 6 months in UC improved the results of conventional treatment with mesalazine and prednisone.

In our study, UC patients undergoing antibacterial therapy have been determined to be 2.17 -fold more likely to experience clinical remission than patients receiving no antibacterial therapy. Homogeneity among the trials was established based on a graphic display (Fig. 2) and statistical tests. In addition, meta-analysis of short-term antibacterial trials revealed that 5-180 days of antibiotic therapy is effective for clinical remission. These results were clinically and statistical significant.

However, a lack of well-designed, placebo-controlled trials has made the efficacy of antibiotics as the primary treatment for IBD questionable. Poor study design, high drop-out rates and insufficient numbers of subjects in the current studies have led to negative or equivocal results causing further controversy.

To date, these studies have provided sufficient evidence that antibiotics have been useful in the treatment of this disease. The use of antibiotics in patients with IBD, however, is controversial. The treatment of experimental IBD with antibiotics may have contradictory results, since it remains unclear which bacteria cause the disease. Moreover, many organisms which grow in the gut mucosa, where they are more resistant to standard antibiotic treatment, may not be able to reach the mucosal surface. Susceptibility testing of organisms has not been carried out in a systematic manner, and antibiotic treatment is not aimed at specific bacteria. In fact, other clinical infections may be present. It would be a difficult and time-consuming task to complete in clinical practice if multiple varieties of bacteria were involved. This is due to the requirement for the mucosal microbial flora of each patient to be characterized and a drug sensitivity test on each patient to be carried out.

Therefore, to determine the effect of antibiotics in the treatment of IBD, larger randomized clinical trials of antibiotics should be carried out, either in solo or combined with other antibiotics or therapies.

\section{References}

1. Sartor RB: Therapeutic manipulation of the enteric microflora in inflammatory bowel diseases: antibiotics, probiotics, and prebiotics. Gastroenterology 126: 1620-1633, 2004.

2. Duchman R, Kaiser I, Hermann E, et al: Tolerance exists towards resident intestinal flora but is broken in active inflammatory bowel disease (IBD). Clin Exp Immunol 102: 448-455, 1995.

3. Podolsky DK: Inflammatory bowel disease. N Engl J Med 347: 417-429, 2002.

4. Prantera $\mathrm{C}$ and Scribano ML: Antibiotics and probiotics in inflammatory bowel disease: why, when, and how. Curr Opin Gastroenterol 25: 329-333, 2009.

5. Sandborn WJ and Feagan BG: Review article: mild to moderate Crohn's disease - defining the basis for a new treatment algorithm. Aliment Pharmacol Ther 18: 263-277, 2003.

6. Sutherland L, Singleton J, Sessions J, Hanauer S, Krawitt E, Rankin G, Summers R, Mekhjian H, Greenberger N and Kelly M: Double blind, placebo controlled trial of metronidazole in Crohn's disease. Gut 32: 1071-1075, 1991.

7. Steinhart AH, Feagan BG, Wong CJ, Vandervoort M, Mikolainis S, Croitoru K, Seidman E, Leddin DJ, Bitton A, Drouin E, et al: Combined budesonide and antibiotic therapy for active Crohn's disease: a randomized controlled trial. Gastroenterology 123: 33-40, 2002.

8. Prantera C, Lochs H, Campieri M, Scribano ML, Sturniolo GC, Castiglione $\mathrm{F}$ and Cottone $\mathrm{M}$ : Antibiotic treatment of Crohn's disease: results of a multicentre, double blind, randomized, placebo-controlled trial with rifaximin. Aliment Pharmacol Ther 23: 1117-1125, 2006.

9. Arnold GL, Beaves MR, Pryjdun VO and Mook WJ: Preliminary study of ciprofloxacin in active Crohn's disease. Inflamm Bowel Dis 8: 10-15, 2002.

10. West RL, van der Woude CJ, Hansen BE, et al: Clinical and endosonographic effect of ciprofloxacin on the treatment of perianal fistulae in Crohn's disease with infliximab: a doubleblind placebo-controlled study. Aliment Pharmacol Ther 20: 1329-1336, 2004 
11. Leiper K, Martin K, Ellis A, et al: Clinical trial: randomized study of clarithromycin versus placebo in active Crohn's disease. Aliment Pharmacol Ther 27: 1233-1239, 2008.

12. Goodgame RW, Kimball K, Akram S, Ike E, Ou CN, Sutton F and Graham D: Randomized controlled trial of clarithromycin and ethambutol in the treatment of Crohn's disease. Aliment Pharmacol Ther 15: 1861-1866, 2001.

13. Blichfeldt P, Blomhoff JP, Myhre E and Gjone E: Metronidazole in Crohn's disease. A double blind cross-over clinical trial. Scand J Gastroenterol 13: 123-127, 1978.

14. Ambrose NS, Allan RN, Keighley MR, et al: Antibiotic therapy for treatment in relapse of intestinal Crohn's disease. A prospective randomized study. Dis Colon Rectum 28: 81-85, 1985.

15. Selby W, Pavli P, Crotty B, et al: Two-year combination antibiotic therapy with clarithromycin, rifabutin, and clofazimine for Crohn's disease. Gastroenterology 132: 2313-2319, 2007.

16. Colombel JF, Lémann M, Cassagnou M, et al: A controlled trial comparing ciprofloxacin and mesalamine for the treatment of active Crohn's disease. Groupe d'Etudes Therapeutiques des Affections Inflammatoires Digestives (GETAID). Am J Gastroenterol 94: 674-678, 1999.

17. Cho JH and Weaver CT: The genetics of inflammatory bowel disease. Gastroenterology 133: 1327-1339, 2007.

18. Kobayashi KS, Chamaillard M, Ogura Y, et al: Nod2-dependent regulation of innate and adaptive immunity in the intestinal tract. Science 307: 731-734, 2005.

19. Barnich N and Darfeuille-Michaud A: Adherent-invasive Escherichia coli and Crohn's disease. Curr Opin Gastroenterol 23: 16-20, 2007.

20. Issa M, Vijayapal A, Graham MB, et al: Impact of Clostridium difficile on inflammatory bowel disease. Clin Gastronterol Hepatol 5: 345-351, 2007.

21. Greenbloom SL, Steinhart AH and Greenberg GR: Combination ciprofloxacin and metronidazole for active Crohn's disease. Can J Gastroenterol 12: 53-56, 1998.

22. Carter MJ, Lobo AJ, Travis SP, et al: Guidelines for the management of inflammatory bowel disease in adults. Gut 53 (Suppl 5): V1-V16, 2004.
23. Gilat T, Suissa A, Leichtman G, et al: A comparative study of metronidazole and sulfasalazine in active, not severe, ulcerative colitis. An Israeli multicenter trial. J Clin Gastroenterol 9: 415-417, 1987.

24. Chapman RW, Selby WS and Jewell DP: Controlled trial of intravenous metronidazole as an adjunct to corticosteroids in severe ulcerative colitis. Gut 27: 1210-1212, 1986.

25. Mantzaris GJ, Archavlis E, Christoforidis P, et al: A prospective randomized controlled trial of oral ciprofloxacin in acute ulcerative colitis. Am J Gastroenterol 92: 454-456, 1997.

26. Mantzaris GJ, Petraki K, Archavlis E, et al: A prospective randomized controlled trial of intravenous ciprofloxacin as an adjunct to corticosteroids in acute, severe ulcerative colitis. Scand J Gastroenterol 36: 971-974, 2001.

27. Mantzaris GJ, Hatzis A, Kontogiannis P and Triadaphyllou G: Intravenous tobramycin and metronidazole as an adjunct to corticosteroids in acute, severe ulcerative colitis. Am J Gastroenterol 89: 43-46, 1994

28. Burke DA, Axon AT, Clayden SA, et al: The efficacy of tobramycin in the treatment of ulcerative colitis. Aliment Pharmacol Ther 4: 123-129, 1990.

29. Gionchetti P, Rizzello F, Ferrieri A, et al: Rifaximin in patients with moderate or severe ulcerative colitis refractory to steroidtreatment: a double-blind, placebo-controlled trial. Dig Dis Sci 44: 1220-1221, 1999.

30. Turunen U, Färkkilä MA, Hakala K, et al: Long-term treatment of ulcerative colitis with ciprofloxacin: a prospective, double-blind, placebo-controlled study. Gastroenterology 115: 1072-1078, 1998.

31. Ohkusa T, Nomura T, Terai T, et al: Effectiveness of antibiotic combination therapy in patients with active ulcerative colitis: a randomized, controlled pilot trial with long-term follow-up. Scand J Gastroenterol 40: 1334-1342, 2005.

32. Ohkusa T, Kato K, Terao S, et al: Newly developed antibiotic combination therapy for ulcerative colitis: a double-blind placebo-controlled multicenter trial. Am J Gastroenterol 105: 1820-1829, 2010. 